\title{
(2) armenam \\ () \\ OPEN ACCESS \\ Amantadine treatment is associated with improved consciousness in patients with non-traumatic brain injury
}

\author{
Lena Rühl, Joji B Kuramatsu 두 , Jochen A Sembill, Bernd Kallmünzer,

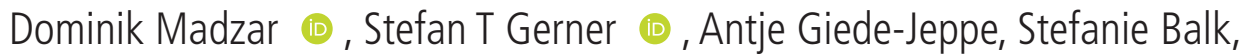 \\ Tamara Mueller, Jakob Jäger, Stefan Schwab, Hagen B Huttner, Maximilian I Sprügel
}

- Additional supplemental material is published online only. To view, please visit the journal online (http://dx. doi.org/10.1136/jnnp-2021 327408).

Department of Neurology, Friedrich-Alexander-Universität Erlangen-Nürnberg, Erlangen, Germany

Correspondence to Dr Maximilian I Sprügel, Department of Neurology, Friedrich-Alexander-Universität Erlangen-Nürnberg, Erlangen, Bayern, Germany; maximilian. spruegel@uk-erlangen.de

Received 17 June 2021 Accepted 29 December 2021

Check for updates

(C) Author(s) (or their employer(s)) 2022. Re-use permitted under CC BY-NC. No commercial re-use. See rights and permissions. Published by BMJ.

To cite: Rühl L, Kuramatsu JB, Sembill JA, et al. J Neurol Neurosurg Psychiatry Epub ahead of print: [please include Day Month Year]. doi:10.1136/jnnp-2021327408

\section{ABSTRACT \\ Objective This study determined the effect of} amantadine treatment on consciousness in patients with non-traumatic brain injury.

Methods We pooled individual patient data of five single-centre observational studies to determine the effect of amantadine treatment among patients with ischaemic stroke, intracerebral haemorrhage, subarachnoid haemorrhage, community-acquired bacterial meningitis and status epilepticus, admitted between January 2012 and December 2015 and ventilated $\geq 7$ days. Patient selection and multivariable regression modelling were used to adjust for differences in intergroup comparison and for parameters associated with consciousness. Improvement of consciousness 5 days after treatment initiation was defined as primary outcome. Secondary outcomes included Glasgow Coma Scale (GCS) at day 5 and GCS at day 10, rate of ICU delirium, epileptic seizures and all-cause mortality at 90 days.

Results Overall, 84 of 294 (28.6\%) eligible patients received amantadine. Amantadine treatment was associated with improvement of consciousness at day 5 (amantadine: $86.9 \%$ vs control: $54.0 \%$; absolute difference: 32.9 (20.0-44.2); adjusted OR (aOR): 5.71 (2.50-13.05), $p<0.001)$. Secondary outcomes showed differences in GCS 5 days (9 (8-11) vs $6(3-9), p<0.001)$ and GCS 10 days $(10(8-11)$ vs $9(6-11), p=0.003)$ after treatment initiation. There were no significant differences regarding all-cause mortality (aOR: 0.89 (0.44-1.82) $p=0.758$ ) and ICU delirium (aOR: 1.39 (0.58-3.31), $p=0.462$ ). Rate of epileptic seizures after initiation of amantadine treatment was numerically higher in the amantadine group (amantadine: $10.7 \%$ vs control: 3.0\%; absolute difference: 7.7 (0.3-16.4); aOR: 3.68 (0.86-15.71), $p=0.079$ ).

Conclusions Amantadine treatment is associated with improved consciousness among patients with different types of non-traumatic brain injury in this observational cohort analysis. Epileptic seizures should be considered as potential side effects and randomised controlled trials are needed to confirm these findings.

\section{INTRODUCTION}

Globally, there are approximately 55 million people living with disability related to traumatic brain injury (TBI) and 80 million with disability related to stroke. ${ }^{12}$ Rehabilitation should be initiated early after brain injury to ensure recovery and prevent long-term disability. ${ }^{3-5}$ However, patients with severe brain injury frequently suffer from impaired consciousness undermining rehabilitation and functional recovery. ${ }^{36}$ Moreover, prolonged impairment of consciousness may result in unjustified care limitation and worse patient outcome by selffulfilling prophecy. ${ }^{7-10}$

Amantadine, an N-methyl-D-aspartate receptor antagonist and indirect dopamine agonist, exerts effects on multiple neurotransmitters and is used as neurostimulant in patients with prolonged disorders of consciousness. ${ }^{1112}$ A randomised controlled trial and several observational studies showed that amantadine accelerated functional recovery in TBI. ${ }^{1314}$ Regarding non-TBI (NTBI), amantadine is frequently administered in patients with impaired consciousness, but its effect in the acute care setting remains to be verified and evidence is based on case reports and cohort studies with limited patient numbers $(n \leq 12)$ or lack of a control group. ${ }^{12} 14-18$ Seizures have been reported as side effect of amantadine administration, why amantadine may also exert detrimental effects in patients with NTBI. ${ }^{19}$

The present study pooled individual patient data (IPD) of five observational studies to investigate the effect of amantadine treatment on (1) consciousness, rate of (2) mortality, (3) ICU delirium and (4) epileptic seizures.

\section{METHODS}

Study design and patient selection

The present study pooled IPD of five observational studies conducted at the university hospital Erlangen, a tertiary care centre in Germany. Patients with primary spontaneous intracerebral haemorrhage $(\mathrm{ICH})$ from the prospective Univerisitätsklinikum Erlangen Cohort of Patients With Spontaneous Intracerebral Haemorrhage study, ${ }^{20} 21$ patients with ischaemic stroke (IS) from a prospective stroke registry, ${ }^{22}$ patients with subarachnoid haemorrhage $(\mathrm{SAH})$ from a prospective institutional $\mathrm{SAH}$ registry, ${ }^{23}$ patients with community-acquired bacterial meningitis (CABM) from a prospective institutional registry, ${ }^{24}$ and patients with status epilepticus (SE) from a retrospectively established institutional SE database ${ }^{25}$; admitted to the 
neurological intensive care unit (ICU) between 1 January 2012 and 31 December 2015 and ventilated $\geq 7$ days were included. All studies were approved by the local institutional review board and patients or legal representatives provided informed consent unless waived by the review board. ${ }^{2022-25}$

\section{Definitions and data acquisition}

Data on demographics, clinical admission status and in-hospital parameters were assessed as previously published. ${ }^{20} 22-27$ Diagnosis of ICH, IS and SAH was established based on clinical findings and first cranial imaging scans after symptom onset. ${ }^{23} 28$ Diagnosis of CABM was confirmed by cerebrospinal fluid, laboratory and clinical findings. ${ }^{24} 29$ SE was defined as clinically or electroencephalographically persisting seizure $\geq 5 \mathrm{~min}$ or as a series of seizures without interictal recovery. ${ }^{25}{ }^{30}$ Glasgow Coma Scale (GCS; at hospital admission and thereafter assessed daily at the ICU bedside at 10:00 am ( \pm 4 hours)), ventilation parameters and amantadine treatment (ie, dosage, time, duration and route of administration) were recorded as noted in medical charts and prospective databases. ICU delirium was defined as delirium diagnosed by attending physicians based on the Confusion Assessment Method for the Intensive Care Unit. ${ }^{31}$ Epileptic seizures were defined as electrographic evidence of ictal activity on electroencephalography (EEG) with or without corresponding clinical symptoms or signs, or witnessed clinical symptoms or signs diagnosed as epileptic seizure by the attending neurologist. ${ }^{32}$ Amantadine treatment was defined as intravenous and/or oral administration of at least a single dose of at least $100 \mathrm{mg}$ amantadine with the intention to improve patients' consciousness. Amantadine treatment was considered in patients with GCS score of 6 or less by standard clinical practice at the institution, but initiation and timing of amantadine were at the discretion of the attending physician. Amantadine administered for other indications such as Parkinson's disease was not considered as amantadine treatment. Amantadine treatment was categorised according to timing of treatment initiation as early (ie, administration of the first dose within $3 \pm 2$ days after weaning initiation), delayed (within $8 \pm 2$ days) and late (within $13 \pm 2$ days) treatment.

\section{Outcome measures}

Primary outcome

Improvement of consciousness at day 5 was defined as primary outcome characterised as increase in GCS score of at least 3 points within 5 days after initiation (treatment group) or consideration (control group) of amantadine treatment. ${ }^{16}$

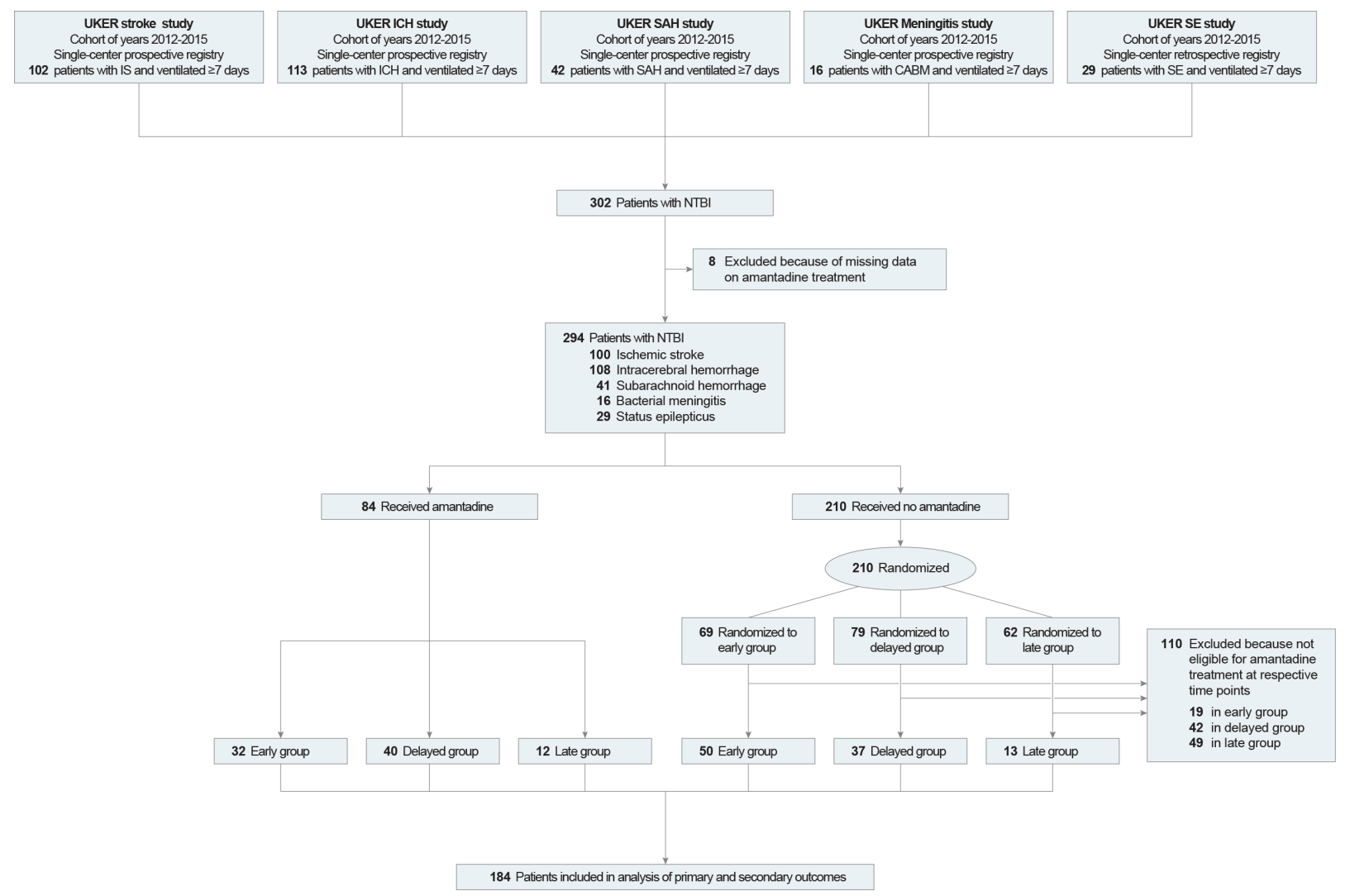

Figure 1 Flow chart of study participants. Overall, 302 patients with different NTBI and mechanical ventilation $\geq 7$ days were recruited between 1 January 2012 until 31 December 2015; 102 with IS, 113 patients with ICH, 42 with SAH, 16 with CABM and 29 with SE. After exclusion of eight patients because of missing data on amantadine treatment, the study sample consisted of 294 patients. In the control group, patients were randomised (1:1:1) to one of the three categories of treatment initiation (early, delayed and late) and patients who were not eligible for amantadine treatment at respective time points (GCS $>6$ at each day of the corresponding categories of treatment initiation: day 1 until day 5 for early treatment initiation group, day 6 until day 10 for delayed group and day 11 until day 15 for late group) were excluded. Afterwards, there were 84 patients in the amantadine group and 100 patients in the control group. Patients in the SE registry could be included repeatedly for separate episodes of SE, but patients included in outcome analysis of amantadine treatment were all different individual patients. CABM, community-acquired bacterial meningitis; ICH, intracerebral haemorrhage; IS, ischaemic stroke; NTBI, non-traumatic brain injury; SAH, subarachnoid haemorrhage; SE, status epilepticus; UKER, Universitätsklinikum Erlangen;. 
Table 1 Clinical characteristics of the study cohort

\begin{tabular}{|c|c|c|c|}
\hline & $\begin{array}{l}\text { Amantadine group } \\
(n=84)\end{array}$ & $\begin{array}{l}\text { Control group } \\
(n=100)\end{array}$ & $P$ value \\
\hline Age, years (IQR) & $76(69-80)$ & $65(57-74)$ & $<0.001$ \\
\hline Female sex, number (\%) & $36(42.9)$ & $42(42.0)$ & 0.907 \\
\hline \multicolumn{4}{|l|}{ Type of disease, number (\%) } \\
\hline Ischaemic stroke & $34(40.5)$ & $30(30.0)$ & 0.137 \\
\hline Intracerebral haemorrhage & $33(39.3)$ & $34(34.0)$ & 0.458 \\
\hline Subarachnoid haemorrhage & $8(9.5)$ & $16(16.0)$ & 0.194 \\
\hline $\begin{array}{l}\text { Community-acquired bacterial } \\
\text { meningitis }\end{array}$ & $4(4.8)$ & $6(6.0)$ & 0.757 \\
\hline Status epilepticus & $5(6.0)$ & $14(14.0)$ & 0.074 \\
\hline \multicolumn{4}{|c|}{ Amantadine treatment initiation/consideration, number (\%) } \\
\hline Early treatment* & $32(38.1)$ & $50(50.0)$ & 0.106 \\
\hline Delayed treatment $\dagger$ & $40(47.6)$ & $37(37.0)$ & 0.146 \\
\hline Late treatment‡ & $12(14.3)$ & $13(13.0)$ & 0.800 \\
\hline \multicolumn{4}{|l|}{ Hospital parameters (IQR) } \\
\hline GCS on admission & $10(3-13)$ & $9(9-13)$ & 0.947 \\
\hline GCS at treatment initiation & $5(4-5)$ & $4(3-6)$ & 0.367 \\
\hline $\begin{array}{l}\text { Duration of ventilation until } \\
\text { weaning initiation, days }\end{array}$ & $2.61(1.28-4.85)$ & $3.92(2.56-8.53)$ & 0.001 \\
\hline $\begin{array}{l}\text { Time from symptom onset } \\
\text { to amantadine treatment/ } \\
\text { consideration, days }\end{array}$ & $10.74(7.87-14.09)$ & $12.41(7.70-15.84)$ & 0.200 \\
\hline \multicolumn{4}{|c|}{$\begin{array}{l}\text { *Early treatment was defined as administration of the first dose of amantadine within } 3 \pm 2 \text { days after } \\
\text { weaning initiation. } \\
\text { †Delayed treatment was defined as treatment initiation within } 8 \pm 2 \text { days. } \\
\text { fLate treatment was defined as treatment initiation within } 13 \pm 2 \text { days. } \\
\text { GCS, Glasgow Coma Scale. }\end{array}$} \\
\hline
\end{tabular}

\section{Secondary outcomes}

Secondary efficacy outcomes comprised (1) improvement of consciousness at day 10 defined as increase in GCS score of at least 3 points within 10 days after initiation of amantadine treatment, (2) GCS at day 5, (3) GCS at day 10 after initiation of amantadine treatment, (4) emergence from unconsciousness at day 5 defined as demonstration of localisation or command following or confused communication or better within 5 days after initiation of amantadine treatment, (5) emergence from unconsciousness at day 10 and (6) all-cause mortality rate at day 90 after hospital admission. Secondary safety outcomes were (7) rate of ICU delirium and (8) rate of epileptic seizures after initiation of amantadine treatment. GCS at day 5 and GCS at day 10 were defined as GCS assessed at day 5 and, respectively, at day 10 after initiation of amantadine treatment or at hospital discharge, whichever came first.

\section{Statistical analyses}

SPSS V.21.0 and Excel V.16.0 were used for statistical analyses, Excel V.16.0 and Adobe Illustrator V.24.3 for graphical illustration. Results are presented as mean $( \pm \mathrm{SD})$ or median $(\mathrm{IQR})$ or number of events (percentage). Categorial variables were compared by the Pearsons $\chi^{2}$ test or the Fisher's exact test, respectively. ${ }^{5}{ }^{28}$ Ordinal variables and non-normally distributed continuous variables were compared by the MannWhitney U-test, normally distributed continuous variables by the Student's t-test. ${ }^{528}$

To minimise bias by timing of treatment initiation, we randomised (1:1:1) patients in the control group to one of the three categories of treatment initiation (early, delayed and late) and afterwards excluded patients who were not eligible for amantadine treatment at respective time points (GCS $>6$ at each day of the corresponding categories of treatment initiation: day 1 until day 5 for early treatment initiation group, day 6 until day 10 for delayed group and day 11 until day 15 for late group). Multivariable regression analyses were adjusted for parameters showing significant differences in intergroup comparison and for parameters associated with consciousness (GCS at day 5 or day 10) after initiation of amantadine treatment in univariate analysis $(p<0.05)$. Significance levels of the secondary outcomes were adjusted for multiplicity using Bonferroni-Holm method.

Subgroup analyses were conducted for the primary outcome among the subgroups of patients according to age ( $\leq 70$ years $>70$ years), sex (women, men), type of disease (IS, ICH, SAH, CABM, SE), timing of treatment initiation (early, delayed, late), treatment dosage $(\leq 300 \mathrm{mg},>300 \mathrm{mg})$ and GCS at hospital admission. ${ }^{3-15}$ For exploratory analyses, the time course of GCS values before and after initiation of amantadine treatment was compared between treatment and control group.

\section{RESULTS}

Study population and clinical characteristics

IPD of 302 patients with different NTBI and mechanical ventilation $\geq 7$ days were pooled. After exclusion of eight patients because of missing data on amantadine treatment, the study sample consisted of 294 patients (figure 1). Overall, 84 of 294

\begin{tabular}{|c|c|c|c|c|c|}
\hline Outcomes & $\begin{array}{l}\text { Amantadine group } \\
(n=84)\end{array}$ & $\begin{array}{l}\text { Control group } \\
(n=100)\end{array}$ & $\begin{array}{l}\text { Absolute difference } \\
(95 \% \mathrm{Cl})\end{array}$ & $\begin{array}{l}\text { Adjusted } \\
\text { OR }(95 \% \mathrm{Cl})\end{array}$ & $P$ value \\
\hline \multicolumn{6}{|l|}{ Primary } \\
\hline Improvement of consciousness at day 5, number/total (\%) & $73 / 84(86.9)$ & $54 / 100(54.0)$ & $32.9(20.0$ to 44.2$)$ & 5.71 (2.50 to 13.05$)$ & $<0.001$ \\
\hline \multicolumn{6}{|l|}{ Secondary efficacy } \\
\hline Improvement of consciousness at day 10, number/total (\%) & $77 / 84(91.7)$ & $67 / 100(67.0)$ & $24.7(13.1$ to 35.3$)$ & 5.34 (2.03 to 14.04$)$ & $0.001^{*}$ \\
\hline GCS at day 5 , median (IQR) & $9(8-11)$ & $6(3-9)$ & & & $<0.001^{*}$ \\
\hline GCS at day 10 , median (IQR) & $10(8-11)$ & $9(6-11)$ & & & $0.003^{*}$ \\
\hline Emergence from unconscious-ness at day 5, number/total (\%) & $66 / 84(78.6)$ & $49 / 100(49.0)$ & 29.6 (15.7 to 41.7$)$ & $4.04(1.92$ to 8.51$)$ & $<0.001^{*}$ \\
\hline Emergence from unconscious-ness at day 10, number/total $(\%)$ & $69 / 84(82.1)$ & $59 / 100(59.0)$ & 23.1 (9.9 to 35.0$)$ & 3.07 (1.42 to 6.63$)$ & 0.004 * \\
\hline $\begin{array}{l}\text { All-cause mortality at } 90 \text { days, } \\
\text { number/total (\%) }\end{array}$ & $32 / 80(40.0)$ & 29/94 (30.9) & $9.2(-5.0$ to 23.0$)$ & 0.89 (0.44 to 1.82$)$ & 0.758 \\
\hline \multicolumn{6}{|l|}{ Secondary safety } \\
\hline ICU delirium, number/total (\%) & 15/84 (17.9) & $15 / 100(15.0)$ & $2.9(-7.8$ to 14.0$)$ & $1.39(0.58$ to 3.31$)$ & 0.462 \\
\hline Epileptic seizures, number/total (\%) & 9/84 (10.7) & $3 / 100(3.0)$ & 7.7 (0.3 to 16.4$)$ & $3.68(0.86$ to 15.71$)$ & 0.079 \\
\hline
\end{tabular}

*Significant after Bonferroni-Holm correction.

GCS, Glasgow Coma Scale; ICU, intensive care unit. 
patients (28.6\%) received amantadine; 34/100 (34.0\%) in IS, $33 / 108(30.6 \%)$ in $\mathrm{ICH}, 8 / 41(19.5 \%)$ in SAH, 4/16 (25.0\%) in CABM and $5 / 29(17.2 \%$ ) in SE (see online supplemental table 1 ). Treatment was initiated early (ie, within $3 \pm 2$ days after weaning initiation) in 32 of 84 patients (38.1\%), delayed (within $8 \pm 2$ days) in $40(47.6 \%)$ and late (within $13 \pm 2$ days) in 12 $(14.3 \%)$ patients (see online supplemental figure 1$)$. To account for timing of treatment initiation, we randomised patients in the control group to one of the three groups of treatment initiation (early, delayed and late) and afterwards excluded patients who were not eligible for amantadine treatment at respective time points (figure 1).

The final study sample consisted of 184 patients, of which 84 $(45.7 \%)$ received amantadine treatment (table 1$)$. There were $42.4 \%$ women and the median (IQR) age at hospital admission was $71(60-78)$ years. Data on all-cause mortality at 90 days were available for 174 of $184(94.6 \%)$ patients and mortality at 3 months was $35.1 \%$. One patient in the control group received amantadine for other indications. Patients in the amantadine group were older (amantadine: 76 (69-80) years vs control: 65 $(57-74)$ years; $p<0.001)$, whereas patients in the control group had longer duration of mechanical ventilation before weaning initiation (amantadine: $2.61 \quad(1.28-4.85)$ days vs control: 3.92 (2.56-8.53) days; $\mathrm{p}=0.001)$. There were no statistically significant differences regarding time from symptom onset to amantadine treatment initiation/consideration (amantadine: 10.74 (7.87-14.09) days vs control: 12.41 (7.70-15.84) days; $\mathrm{p}=0.200)$. Outcome analyses were performed using multivariable regression analysis adjusted for age and duration of mechanical ventilation and additionally for GCS at treatment initiation as variable associated with consciousness $(p<0.05$ for the association with improvement of consciousness at day 5 and at day 10 in univariate analysis).

\section{Analysis of primary and secondary outcomes \\ Primary outcome}

Regarding the primary outcome, amantadine treatment was associated with improvement of consciousness at day 5 (amantadine: 73/84 (86.9\%) vs control: 54/100 (54.0\%); absolute difference: 32.9 (20.0 to 44.2); adjusted OR (aOR): 5.71 (2.50-13.05), $\mathrm{p}<0.001$; table 2).

\section{Secondary outcomes}

Regarding secondary efficacy outcomes, amantadine treatment was associated with improvement of consciousness at day 10 (amantadine: 77/84 (91.7\%) vs control: 67/100 (67.0\%); absolute difference: 24.7 (13.1-35.3); aOR: 5.34 (2.03-14.04), $\mathrm{p}=0.001$; table 2). There were significant differences in GCS at day 5 (amantadine: 9 (8-11) vs control: 6 (3-9), p<0.001) and at day 10 (amantadine: $10(8-11)$ vs control: 9 (6-11), $\mathrm{p}=0.003$; table 2 and figure 2$)$. Amantadine treatment was associated emergence from unconsciousness at day 5 (amantadine: 66/84 (78.6\%) vs control: 49/100 (49.0\%); absolute difference: 29.6 (15.7-41.7); aOR: 4.04 (1.92-8.51), p<0.001) and at day 10 (amantadine: 69/84 (82.1\%) vs control: 59/100 (59.0\%); absolute difference: 23.1 (9.9-35.0); aOR: 3.07 (1.42-6.63), $\mathrm{p}=0.004)$. Rate of all-cause mortality at 90 days (amantadine: 32/80 (40.0\%) vs control: 29/94 (30.9\%), aOR: 0.89 (0.44$1.82), \mathrm{p}=0.758$ ) was not different across treatment groups.

Regarding secondary safety outcomes, rate of ICU delirium (amantadine: 15/84 (17.9\%) vs control: 15/100 (15.0\%); 
A

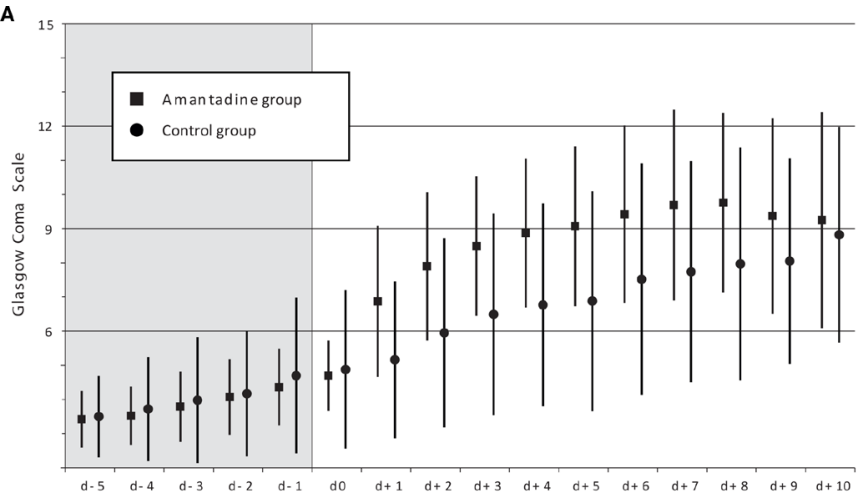

B

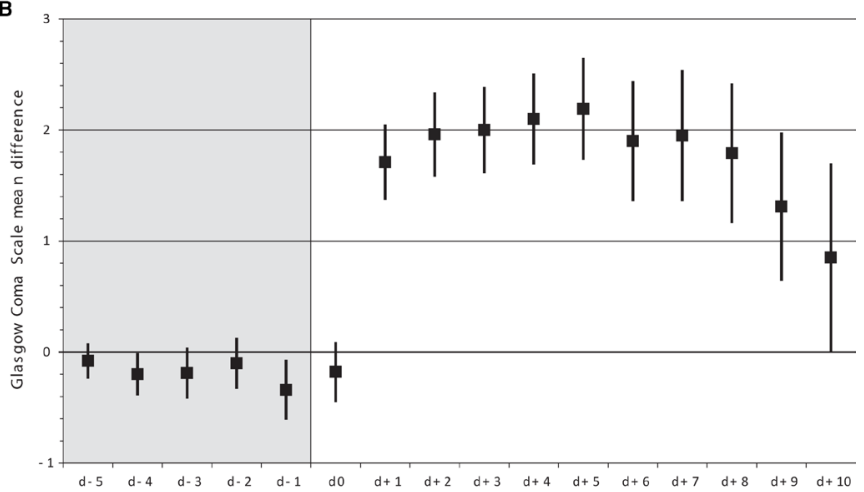

Days before and after amantadine treatment initiation

Figure 3 Exploratory analyses regarding the time course of consciousness. Illustration of the time course of consciousness from 5 days before amantadine treatment initiation (shown in light grey) until 10 days thereafter, $\mathrm{d} 0$ represents the day of amantadine treatment initiation. (A) For exploratory illustration, mean values of GCS were calculated for amantadine group (square) and control group (circle). Points represent the mean and thin lines the SD. (B) For exploratory illustration, mean differences of GCS values between amantadine group and control group were calculated. Points represent the mean difference and thin lines the $95 \% \mathrm{Cl}$. Patients discharged from hospital before respective days of GCS assessment were not accounted for (secondary outcome analysis of GCS at day 5 and GCS at day 10 included GCS at hospital discharge for these patients). GCS, Glasgow Coma Scale; NTBI, non-traumatic brain injury.

absolute difference: 2.9 (-7.8 to 14.0$)$; aOR: 1.39 (0.58-3.31), $\mathrm{p}=0.462$ ) did not differ across treatment groups. There was a non-significant difference regarding the rate of epileptic seizures after initiation of amantadine treatment (amantadine: 9/84 (10.7\%) vs control: 3/100 (3.0\%); absolute difference: 7.7 (0.316.4); aOR: 3.68 (0.86-15.71), $\mathrm{p}=0.079)$. Continuous EEG monitoring was performed in 130 of 184 (70.7\%) patients, 8 of $12(66.7 \%)$ seizure events were non-convulsive seizures (first seizure event that occurred in patients with seizures after treatment initiation).

\section{Subgroup and exploratory analyses}

Subgroup analyses were performed for the primary outcome, improvement of consciousness at day 5 (figure 2). Treatment effects of amantadine were not significantly different among subgroups of patients according to age, GCS at hospital admission, timing of treatment initiation and treatment dosage (aOR: s600 mg: 4.80 (1.74-13.26), >600 mg: 9.64 (1.15-80.50); $\mathrm{p}$ value for interaction: 0.562$)$. Treatment effects tended to be modified by type of disease (aOR: IS: 4.23 (0.89-20.10), ICH:
8.77 (1.96-39.34); SAH: 4.59 (0.31-67.90); CABM: 0.83 (0.02-35.25); SE: $1.55(0.07-32.84)$; $\mathrm{p}$ value for interaction: $0.077)$.

Exploratory analyses regarding the time course of consciousness measured by the GCS are shown in figure 3. There were no relevant differences between amantadine and control group within 5 days before amantadine treatment initiation (figure $3 \mathrm{~A}$ ). After treatment initiation, consciousness of patients in the amantadine was improved compared with the control group (figure 3B).

\section{DISCUSSION}

To our knowledge, this study represents the first comprehensive analysis of amantadine treatment in NTBI. We found that amantadine treatment is associated with improved consciousness and may represent a viable treatment option for patients with prolonged disorders of consciousness, but epileptic seizures should be considered as potential side effect of amantadine.

Amantadine was reported to increase brain metabolism in the frontoparietal network and is widely used as neurostimulant to improve consciousness. ${ }^{11} 1215$ However, sufficient level of clinical evidence is only available for patients with TBI. ${ }^{11} 13$ We here found that amantadine treatment is associated with improvement of consciousness within 5 and 10 days after weaning initiation among patients with NTBI. Treatment effects of amantadine are consistent among patient subgroups. However, amantadine might be more efficient among patients with IS, ICH and SAH, and future studies should focus on these patients.

Regarding clinical outcomes, amantadine was associated with $11 \%$ lower odds of mortality at 90 days compared with the control group. The difference was not statistically significant, but the study was underpowered to show effects on mortality. As improved consciousness facilitates rehabilitation, functional recovery and may prevent long-term disability, future studies should evaluate treatment effects of amantadine on mortality and functional outcomes. ${ }^{311}$

Amantadine exerts different effects on multiple neurotransmitters, which may cause side effects, notably epileptic seizures and delirium. ${ }^{111419}$ Regarding delirium, we here found that amantadine was not associated with a relevant risk of delirium in this observational cohort analysis. Regarding epileptic seizures, Nickels et al reported that generalised seizures occurred in 2 of 12 patients with TBI treated with amantadine. ${ }^{19}$ However, the study did not include a control group and these seizures may represent sequela of TBI, why epileptic seizures have been discussed as potential side effects of amantadine ever since the publication of this study. ${ }^{11} 131417 \mathrm{We}$, here, show that amantadine treatment was associated with a non-significant $7.7 \%$ absolute increase in the rate of epileptic seizures in this observational cohort analysis with routinely performed continuous EEG monitoring. Although these differences were not statistically significant, future studies should consider epileptic seizures as potential side effects of amantadine treatment.

This study has some shortcomings. Bias by indication and timing of treatment initiation may have confounded analyses, the single-centre approach could limit generalisability, and the study was underpowered to evaluate treatment effects of amantadine on mortality, seizures and delirium. Furthermore, assessment of consciousness was based on the GCS, resulting in practical limitations of assessment in intubated patients. 


\section{CONCLUSIONS}

Amantadine treatment was associated with improved consciousness in this observational cohort analysis and may represent a viable treatment option for patients with NTBI with prolonged disorders of consciousness. Randomised controlled trials are needed to confirm these findings and evaluate treatment effects of amantadine on mortality and functional outcomes. Epileptic seizures should be considered as potential side effect of amantadine.

Acknowledgements The present work was performed in (partial) fulfilment of the requirements for obtaining the degree 'Dr. med.' (Lena Rühl).

Contributors Study concept and design: LR, MIS. Acquisition, analysis or interpretation of data: all authors. Drafting of the manuscript: LR, MIS. Critical revision of the manuscript for important intellectual content: all authors. Statistical analysis: LR, MIS (Friedrich-Alexander-Universität [FAU] Erlangen-Nürnberg). MIS accepts full responsibility for the finished work and the conduct of the study, had access to the data, and controlled the decision to publish.

Funding Supported by a research grant (Alz/lko—Sprü/2020) from the Johannes and Frieda Marohn Foundation, University of Erlangen, Germany. The funding had no role in the study design; in the collection, analysis and interpretation of the data; in the writing of the report; and in the decision to submit the paper for publication.

Competing interests JBK reports personal fees from Bayer, personal fees from Bristol-Myers Squibb \& Pfizer, personal fees from Sanofi, and personal fees from Boehringer Ingelheim outside the submitted work. BK reports personal fees from Bayer, personal fees from Bristol-Myers Squibb \& Pfizer and personal fees from Medtronic outside the submitted work. HBH reports personal fees from Boehringer Ingelheim, personal fees from Bayer AG, personal fees from Daiichi Sankyo, grants and personal fees from Novartis, grants and personal fees from Portola Pharmaceuticals, grants and personal fees from Union Chimique Belge Pharma, and grants and personal fees from Medtronic outside the submitted work. MIS reports grants from IZKF and Marohn Foundation.

\section{Patient consent for publication Not applicable.}

Ethics approval This study involves human participants and was approved by the institutional review board, Friedrich-Alexander-University Erlangen-Nuremberg, Germany (Registration Number 115_17B, 48_15BC, 304_16 B, 10_15 B and 33_20 B). Participants gave informed consent to participate in the study before taking part.

Provenance and peer review Not commissioned; externally peer reviewed.

Data availability statement Data are available upon reasonable request. All data relevant to the study are included in the article or uploaded as supplementary information. Data, methods and materials used to conduct the research in the article were carefully documented. The data that support the findings of this study are available from the corresponding author on reasonable request.

Supplemental material This content has been supplied by the author(s). It has not been vetted by BMJ Publishing Group Limited (BMJ) and may not have been peer-reviewed. Any opinions or recommendations discussed are solely those of the author(s) and are not endorsed by BMJ. BMJ disclaims all liability and responsibility arising from any reliance placed on the content. Where the content includes any translated material, BMJ does not warrant the accuracy and reliability of the translations (including but not limited to local regulations, clinical guidelines, terminology, drug names and drug dosages), and is not responsible for any error and/or omissions arising from translation and adaptation or otherwise.

Open access This is an open access article distributed in accordance with the Creative Commons Attribution Non Commercial (CC BY-NC 4.0) license, which permits others to distribute, remix, adapt, build upon this work non-commercially, and license their derivative works on different terms, provided the original work is properly cited, appropriate credit is given, any changes made indicated, and the use is non-commercial. See: http://creativecommons.org/licenses/by-nc/4.0/.

\section{ORCID iDs}

Joji B Kuramatsu http://orcid.org/0000-0002-7630-7880

Dominik Madzar http://orcid.org/0000-0001-8680-9668

Stefan T Gerner http://orcid.org/0000-0001-6020-8290

Maximilian I Sprügel http://orcid.org/0000-0002-1679-9553

\section{REFERENCES}

1 GBD 2016 Traumatic Brain Injury and Spinal Cord Injury Collaborators. Global, regional, and national burden of traumatic brain injury and spinal cord injury, 19902016: a systematic analysis for the global burden of disease study 2016. Lancet Neurol 2019;18:56-87.
2 GBD 2016 Stroke Collaborators. Global, regional, and national burden of stroke, 1990-2016: a systematic analysis for the global burden of disease study 2016. Lancet Neurol 2019; 18:439-58.

3 Winstein CJ, Stein J, Arena R, et al. Guidelines for adult stroke rehabilitation and recovery: a guideline for healthcare professionals from the American heart Association/American stroke association. Stroke 2016:47:e98-169.

4 Haupenthal D, Kuramatsu JB, Volbers B, et al. Disability-adjusted life-years associated with intracerebral hemorrhage and secondary injury. JAMA Netw Open 2021:4:e2115859.

5 Sprügel MI, Kuramatsu JB, Gerner ST, et al. Age-dependent clinical outcomes in primary versus oral anticoagulation-related intracerebral hemorrhage. Int I Stroke 2021;16:83-92.

6 Stocchetti N, Carbonara M, Citerio G, et al. Severe traumatic brain injury: targeted management in the intensive care unit. Lancet Neurol 2017;16:452-64.

7 Zahuranec DB, Brown DL, Lisabeth LD, et al. Early care limitations independently predict mortality after intracerebral hemorrhage. Neurology 2007;68:1651-7.

8 Izzy S, Compton R, Carandang R, et al. Self-fulfilling prophecies through withdrawal of care: do they exist in traumatic brain injury, too? Neurocrit Care 2013;19:347-63.

9 Sembill JA, Castello JP, Sprügel MI, et al. Multicenter validation of the max-ICH score in intracerebral hemorrhage. Ann Neurol 2021;89:474-84.

10 Sembill JA, Gerner ST, Volbers B, et al. Severity assessment in maximally treated ICH patients: the max-ICH score. Neurology 2017;89:423-31.

11 Thibaut A, Schiff N, Giacino J, et al. Therapeutic interventions in patients with prolonged disorders of consciousness. Lancet Neurol 2019:18:600-14.

12 Peoples J, Lopez A, Feeko K. Stimulant use to improve wakefulness following brain injury: a survey of the neurocritical care Society. EC Neurology 2020;12:01-6.

13 Giacino JT, Whyte J, Bagiella E, et al. Placebo-controlled trial of amantadine for severe traumatic brain injury. N Engl J Med 2012:366:819-26.

14 Gagnon DJ, Leclerc AM, Riker RR, et al. Amantadine and modafinil as neurostimulants during post-stroke care: a systematic review. Neurocrit Care 2020;33:283-97.

15 Schnakers C, Hustinx R, Vandewalle G, et al. Measuring the effect of amantadine in chronic anoxic minimally conscious state. J Neurol Neurosurg Psychiatry 2008;79:225-7.

16 Leclerc AM, Riker RR, Brown CS, et al. Amantadine and modafinil as Neurostimulants following acute stroke: a retrospective study of intensive care unit patients. Neurocrit Care 2021;34:102-11.

17 Gao Y, Zhang Y, Li Z, et al. Persistent vegetative state after severe cerebral hemorrhage treated with amantadine: a retrospective controlled study. Medicine 2020;99:e21822.

18 Akçll EF, Dilmen Özlem Korkmaz, Vehid H, et al. Can amantadine ameliorate neurocognitive functions after subarachnoid haemorrhage? A preliminary study. Turk $J$ Anaesthesiol Reanim 2018:46:100-7.

19 Nickels JL, Schneider WN, Dombovy ML, et al. Clinical use of amantadine in brain injury rehabilitation. Brain Inj 1994;8:709-18.

20 Sprügel MI, Kuramatsu JB, Gerner ST, et al. Antiplatelet therapy in primary spontaneous and oral Anticoagulation-Associated intracerebral hemorrhage. Stroke 2018:49:2621-9.

21 Kuramatsu JB, Biffi A, Gerner ST, et al. Association of surgical hematoma evacuation vs conservative treatment with functional outcome in patients with cerebellar intracerebral hemorrhage. JAMA 2019;322:1392-403.

22 Siedler G, Sommer K, Macha K, et al. Heart failure in ischemic stroke: relevance for acute care and outcome. Stroke 2019;50:3051-6.

23 Gerner ST, Reichl J, Custal C, et al. Long-term complications and influence on outcome in patients surviving spontaneous subarachnoid hemorrhage. Cerebrovasc Dis 2020;49:307-15

24 Giede-Jeppe A, Atay S, Koehn J, et al. Neutrophil-to-lymphocyte ratio is associated with increased cerebral blood flow velocity in acute bacterial meningitis. Sci Rep 2021;11:11383.

25 Madžar D, Reindl C, Giede-Jeppe A, et al. Impact of timing of continuous intravenous anesthetic drug treatment on outcome in refractory status epilepticus. Crit Care 2018;22:317.

26 Sprügel MI, Kuramatsu JB, Volbers B, et al. Perihemorrhagic edema: revisiting hematoma volume, location, and surface. Neurology 2019;93:e1159-70.

27 Sprügel MI, Kuramatsu JB, Volbers B, et al. Impact of statins on hematoma, edema, seizures, vascular events, and functional recovery after intracerebral hemorrhage. Stroke 2021;52:975-84

28 Sprügel MI, Sembill JA, Kuramatsu JB, et al. Heparin for prophylaxis of venous thromboembolism in intracerebral haemorrhage. I Neurol Neurosurg Psychiatry 2019:90:783-91.

29 van de Beek D, Cabellos C, Dzupova O, et al. ESCMID guideline: diagnosis and treatment of acute bacterial meningitis. Clin Microbiol Infect 2016;22 Suppl 3:S37-62.

30 Brophy GM, Bell R, Claassen J, et al. Guidelines for the evaluation and management of status epilepticus. Neurocrit Care 2012;17:3-23.

31 Ely EW, Margolin R, Francis J, et al. Evaluation of delirium in critically ill patients: validation of the confusion assessment method for the intensive care unit (CAM-ICU). Crit Care Med 2001;29:1370-9.

32 Biffi A, Rattani A, Anderson CD, et al. Delayed seizures after intracerebra haemorrhage. Brain 2016;139:2694-705. 